\title{
SUSTAINABLE DEVELOPMENT AND THE PLAN FOR TOURISM IN MEDITERRANEAN COASTAL AREAS: CASE STUDY OF THE REGION OF LIGURIA, ITALY
}

\author{
SELENA CANDIA, FRANCESCA PIRLONE \& ILENIA SPADARO \\ DICCA Department of Civil, Chemical and Environmental Engineering, Genoa University, Italy
}

\begin{abstract}
In the context of land-use planning, sustainable tourism is becoming very important. This paper defines an innovative approach meant to support local authorities in Mediterranean countries in managing this expanding industry. Mediterranean destinations suffer from seasonality and experience many negative impacts related to mass tourism. Tourism has economically positive outcomes, however development related to uncontrolled tourism can lead to very damaging impacts. Managed well, tourism can play a positive role in the environmental, socio-economic and cultural development of a city. This research analyses the main impacts caused by mass tourism, and it proposes, based on current scientific literature, a method to quantify the tourism carrying capacity of a Mediterranean destination. The concept of tourism carrying capacity refers to the maximum number of tourists that can visit a destination at the same time without causing negative impacts. In order to preserve the identity of a tourist attraction, this threshold should not be exceeded. This carrying capacity should be included in all the local plans for tourism. In recent years, many Mediterranean cities have occasionally exceeded their carrying capacity, compromising their natural/urban environment, lifestyle and cultural traditions. The concept of having a carrying capacity is quite understandable and immediate, but its quantification is not so easy. Within the literature, there are a few examples of practical calculations, and yet there is no unified or predominant methodology to obtain comparable results. The authors apply the carrying capacity methodology to two different tourist destinations in the Liguria Region of Italy. The first case study considered is the city centre of Genoa that has in the last few years had an increasing number of visitors but seems to be far from reaching its threshold. The second case is the Cinque Terre Natural Park, a well-known destination that every year attracts thousands of tourists.
\end{abstract}

Keywords: Cinque Terre, Genoa, Mediterranean coast, sustainable tourism, threshold, tourism carrying capacity.

\section{INTRODUCTION}

Over the past six decades, tourism has experienced continued growth and is now considered as one of the fastest growing economic sectors in the world. In 2016, the tourism industry generated over 7.6 trillion US dollars. It is one of the world's largest industries; and according to the United Nations World Tourism Organization (UNWTO), the tourism industry surpasses oil exports and food production. It is a competitive and dynamic sector, and it is deemed to be a key driver for socio-economic progress. International tourist arrivals (overnight visitors) reached a total of 1,235 million people in 2016. This was 46 million more than in 2015 , or an increase of $3.9 \%$. The global pace of growth was slightly more moderate than in $2015(4.5 \%)$, but in line with the long-term forecast of $3.8 \%$ per year for the period of 2010 to 2020, made by UNWTO [1]. France and the U.S. are the most popular destinations, but other countries are quickly emerging.

Tourism can have many positive impacts: it boosts economic growth of a regional economy and supports job creation within it. Outbound tourism promotes cross-cultural understanding and contributes to the fight against prejudice. Many tourist destinations are, however, under threat from their tourism. Cities such as Barcelona, Venice or Dubrovnik 
are struggling to cope with negative impacts related to mass tourism. Too many tourists can have a negative impact on the environment, the quality of life of citizens, and the local culture. Unsustainable forms of tourism allow for vast numbers of travellers to visit a destination during the peak season and in a short time. These forms of tourism are often connected to all-inclusive resorts, cruises, budget-friendly package tours, and cheap flights.

The benefits received by local communities are very few and the resources consumed by the visitors are very high. Sustainable tourism is recognized globally as the only solution to fight against mass tourism. David Weaver stated that "The construct of sustainable tourism emerged during the early 1990s and has since become increasingly established as the dominant paradigm informing the planning and management of the contemporary global tourism sector" [2].

This paper suggests an innovative approach to support sustainable tourism that aims at integrating the tourism carrying capacity methodology into local tourism destinations' strategic planning tools.

In the last five years, an increasing number of cities and countries defined their strategic plan for tourism. These plans aim to ensure effective governance of tourism-related development. The challenge is to manage increasingly numerous tourists and a rapidly evolving market, following the principles of sustainable development.

The methodological approach that we suggest considers two different case studies: the first one, Cinque Terre, has already overpassed the threshold of tourists that is recommended, in order to avoid negative impacts; the second one, the city centre of Genoa, is increasing in tourist arrivals, but does not usually exceed its carrying capacity.

\section{THE TOURISM INDUSTRY AND MEDITERRANEAN DESTINATIONS}

The tourism industry is a key income source for the Mediterranean region, which is famous for being the principal tourist destination in the world. As stated by an EU document on sustainable tourism, "Consequently, tourism plays a vital role in the economies of the region, acting as a significant source of economic growth and employment, while also making a positive contribution to a country's external balance of payments" [3].

The Mediterranean region is renowned for its natural beauty and its historical heritage. It is a perfect destination where is possible to combine different forms of tourism; such as leisure, family, sports, and cultural tourism. This region is made up of 22 countries: 8 of which are EU member states. Tourism has become one of the fastest growing economic sectors over the decades, but the levels and growth rates vary considerably across the different countries of the region. The most visited states are the larger European countries of France, Spain, Italy and Greece; but the most impressive growth rates are in Turkey, Croatia and Albania. In 2016, Mediterranean countries hosted more than 330 million tourists as per the United Nation World Tourism Organisation (UNWTO) in Tourism Highlights (2017): this data is more than double the number recorded in 1995.

Tourism is commonly concentrated in the coastal areas, which receive $30 \%$ of international tourist arrivals. The most widely used tourism development model is based on seaside summer holidays. Over the years, this model led to many seasonal problems; such as during the summer (from July to August), when arrivals in tourist accommodations are almost three times higher than the number of arrivals in the slowest month (January). During summer, millions of tourists who mainly come for the sun, being near the sea and the beach, invade the Mediterranean coasts.

From a macroeconomic perspective, mass tourism phenomena gain in importance; but this tourism is responsible for heavy environmental and social impacts. Tourists provide many economic benefits to Mediterranean countries, but they also interfere with the local 
way of life and the social habits and they consume many resources (such as water, energy, and soil). Manera et al. point out: "The emergence of the environmental question in the tourism industry has reinforced the need for strict coordination between different levels of responsibility: the local and national governments, the entrepreneurial associations, and in general any person connected to an economic or industrial activity in tourism areas" [4].

The fight against environmental impacts is even more significant, given that the Mediterranean region is considered as one of the most important regions in the world for its outstanding biodiversity features. Large-scale mass tourism is one of the main causes behind ecological loss and destruction in the region, particularly in coastal and marine areas that still maintain high natural value and are important for safeguarding biodiversity. Nevertheless, the Mediterranean region is also the cradle of civilization, with a rich and diverse cultural heritage. Social impacts from tourism may determine the loss of local identity and tradition. When many tourists are concentrated in a certain location, cultural conflict may happen. As Borelli et al. state, "With current development models based on quantity, the projected growth of tourism development in the region will continue to damage landscapes, cause soil erosion, put pressure on endangered species, further strain available water resources, increase waste and pollution discharges into the sea and lead to cultural disruption" [5].

Mass tourism is also frequently in conflict with local communities. The economic benefits all too often end up outside of the visited destination, via foreign-owned tour operators, airlines, hotels, imported drinks and food, etc. In addition, local populations compete with tourists for the limited resources of water, energy and land use. So, how is it possible to safeguard the positive aspects of tourism, while minimizing the negative ones? According to the UNWTO, sustainable tourism is the answer. This seems a radical declaration, considering that mass tourism has doubled in the last 20 years, continuing to grow even during the global crisis; and that cruise lines, low-cost flights and all-inclusive tour packages are still very popular. Through inappropriate tourist practices and development, different Mediterranean destinations have been damaged. Venice, Barcelona, and Dubrovnik are examples of destinations where the negative effects related to mass tourism are more evident.

Sustainable tourism has a low impact on the environment and provides local communities with a consistent livelihood. The main goal of mass tourism is to generate revenue; while the main goal of sustainable tourism is to generate cultural experiences. Griffin et al. state: "This new conventional wisdom encourages business to move away from a sole focus on profit to a concern for what has become known as the triple bottom line; that is, financial, social and environmental performance" [6]. Fundamental changes in tourism management are needed; otherwise, mass tourism will seriously damage the diversity and the beauty of the Mediterranean region, as well as its ability to host diverse cultures.

\section{TOURISM CARRYING CAPACITY AND A SUSTAINABLE PLAN FOR TOURISM}

Tourism carrying capacity is defined as "the maximum number of people that may visit a tourist destination at the same time, without causing destruction of the physical, economic, socio-cultural environment and an unacceptable decrease in the quality of visitors' satisfaction" [7].

The concept of carrying capacity is quite understandable and immediate, but its quantification is not so easy. There are few examples of practical calculations in the literature; there is no unified nor predominant methodology, to obtain comparable results. 
The definition of the real carrying capacity of a tourist destination is complex and arriving at results is difficult work. It is necessary to find a way to combine quantitative terms (such as the number of beds in hotels, spaces in parking facilities) and qualitative parameters, such as social or environmental impacts. This combination should also include specific aspects and parameters related to the site under consideration: over- or underexploited areas, urban or natural destinations.

All the components of carrying capacity can be summarized into three main categories in order to simplify things:

- Physical-ecological category: includes accessible space, visual impact, climate, aesthetics, accommodation quality, availability of facilities, transportation, number of people that can be accommodated, the need for conservation, fragility of the environment, wildlife resources, topography, vegetative cover, behavioural sensitivity of species, diversity, uniqueness of species, concealment, resilience of ecosystems or species, impact of use on the area;

- Socio-demographic category: visitors' choice, visitors' opinions, visitors' attitudes and behaviour, expectations and preferences, perceptual and behavioural responses, the response to rising use levels, visitors' activities, visitor satisfaction, acceptable level of crowding, involvement of local communities and/or residents;

- Political-economic category: investments, volume of tourists, holiday cost, level of economic benefits provided, residents' level of enjoyment, legal restraints, incentives included into policy.

In considering carrying capacity in different destinations, the above three components acquire different weight or importance. These differences stem from the place type (characteristics or particularities), the type(s) of tourism present and the tourism/environment interface [8].

One of the most famous examples of determination of social-economic carrying capacity concerns the city of Venice. Using a linear programming model, Costa and Van der Borg indicated the maximum number that historic settlement can support is 25,000 visitors per day (as a combination of 15,000 tourists and 10,000 excursionists). This result considers different capacity restrictions: accommodation availability, catering facilities, parking facilities, transportation and mobility solutions, waste disposal services, and even the space available inside Saint Mark's Cathedral. The linear programming model used was built in order to maximize the income from tourism under the above-mentioned restrictions.

There are different methods used to calculate the carrying capacity of a tourist destination: Linear Programming (LP), Fuzzy Linear Programming (FLP) and Fuzzy Goal Linear Programming (FGLP). Fuzzy logic was introduced in 1965 by Zadeh [9]. It is a mathematic discipline that allows a computer to model the real world as people do. Zadeh stated: "The term fuzzy logic is used in two different senses. In a narrow sense, fuzzy logic is a logical system which aims at a formalisation of approximate reasoning. In a broad sense, fuzzy logic is almost synonymous with fuzzy set theory. Fuzzy set theory is much broader than fuzzy logic in its narrow sense and contains the latter as one of its branches" (Zadeh [9]).

To use the second and third methods, it is essential to define new parameters, having different weight or importance according to the tourist destinations. The methodology proposed here aims at obtaining a first concrete result and collecting some important data. The authors apply Linear Programming (LP) that is based on an economic approach. According to this approach, the maximization of income function deriving from the tourist flow that affects a locality is obtained, supposing that tourism does not have to produce negative effects on the physical, cultural and social environment. 
The income function is maximized according to three different types of tourists who visit a destination: number of hotel tourists $(\mathrm{TH})$, number of non-hotel tourists $(\mathrm{NTH})$, and single day trippers without overnight visits (E). Due to their intrinsic characteristics, these three different types of tourists produce different incomes that are related to their respective average expenses $\left(c_{1}, c_{2}, c_{3}\right)$; therefore, the function of the linear programming problem has three different components that must be added together. This function can be expressed using the equation shown in Fig. 1.

The choice of the constraints is fundamental to the implementation of the model. These constraints make it possible to calculate the inequality needed to solve the linear programming problem. In particular, some restrictions are given by the following categories: HB: number of beds in hotels; NHB: number of beds in extra-hotels/non-hotels; L: number of lunches; P: individual number of available parking positions; WD: solid waste capacity; SMW: max number of people in the case study area.

The carrying capacity should be included in all local plans for tourism. In recent years, in fact, many Mediterranean cities have exceeded (on different occasions) their carrying capacity, compromising their natural/urban environment, lifestyle and cultural traditions.

It is necessary to elaborate an Action Plan aimed at developing an international strategy that is adaptable to local situations. This plan would promote sustainable development at the national level and encourage the creation of networks among different Mediterranean coastal areas, to reduce the impacts of tourism such as: alteration of the landscape, resource exploitation and air pollution.

A research study carried out by the authors Pirlone and Spadaro, published in 2017, defined the contents of a Sustainable Tourism Action Plan (STAP). This STAP must include six different phases:

- Phase 1. Background: problems related to territorial tourism management, European and national tourism legislation, specific goals for the analysed territory, working groups, forum;

- Phase 2. Diagnostic of the state of the art: status quo and analyses, data collection, goals evaluation, SWOT analysis;

- Phase 3. Planning part: design and identification of actions and best practices regarding tourism, connections with other programs in force;

- $\quad$ Phase 4. Application of the plan;

- Phase 5. Plan monitoring, through the identification of specific indicators;

- Phase 6. Awareness and/or participation (this last phase is transversal to the previous ones, considering the importance of participation of all stakeholders).

The research described in this paper seeks to analyse in depth the second phase of the proposed plan, through the introduction of the carrying capacity methodology. The authors defined a methodological approach that at first uses the SWOT and the PEST analyses to obtain objective assessments of the initial state of the area. After that, The STAP aims to

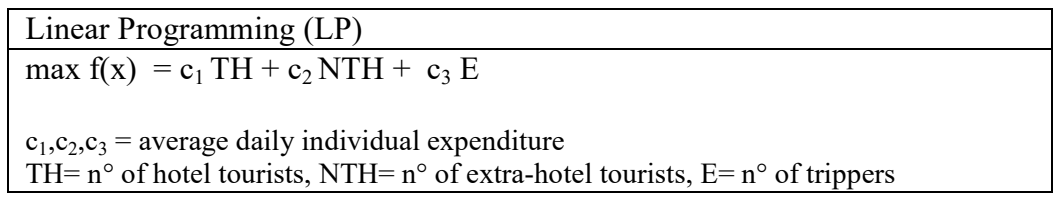

Figure 1: Linear Programming (LP). 
define the strategies and good practices that can be used to support sustainable tourism. At the urban level, the STAP will be an important reference to enhance all governance tools for regional development.

The final objective is to share a strategy between different European countries, particularly those bordering the Mediterranean, which allows for joint management of tourist flows, facilitating their distribution between countries, according to the positive experience of the European Charter for Sustainable Tourism (ECST), working toward a real sustainable tourism based on environmental, social and economic sustainability [10].

\section{CASE STUDIES: THE CITY CENTRE OF GENOA AND CINQUE TERRE NATIONAL PARK}

The innovation presented in this paper concerns the application of the tourism carrying capacity calculations within the STAP. The authors applied this methodology to two different case studies: the city centre of Genoa [11] and Cinque Terre Natural Park.

Cinque Terre National Park is struggling to cope with negative impacts related to mass tourism (Fig. 2). For this reason, it is trying to promote sustainable tourism and to restore a harmonious balance between people and nature. The Cinque Terre area is characterized by a wonderful landscape, but the towns are small and surrounded by a fragile territory that can barely support their two million visitors a year. Visitors must take the train to move from one village to another, because there is no road serving as a connection. This leads to a situation where the trains and railway stations are too crowded.

The situation in the city centre of Genoa is different. Genoa is the capital of the region of Liguria with 592,507 inhabitants: it is the sixth largest city in Italy and the third largest city in the Northern Italy. The city is composed of a narrow coastal zone with hills, and steep mountains in the back country. Genoa is subdivided into nine administrative districts and it

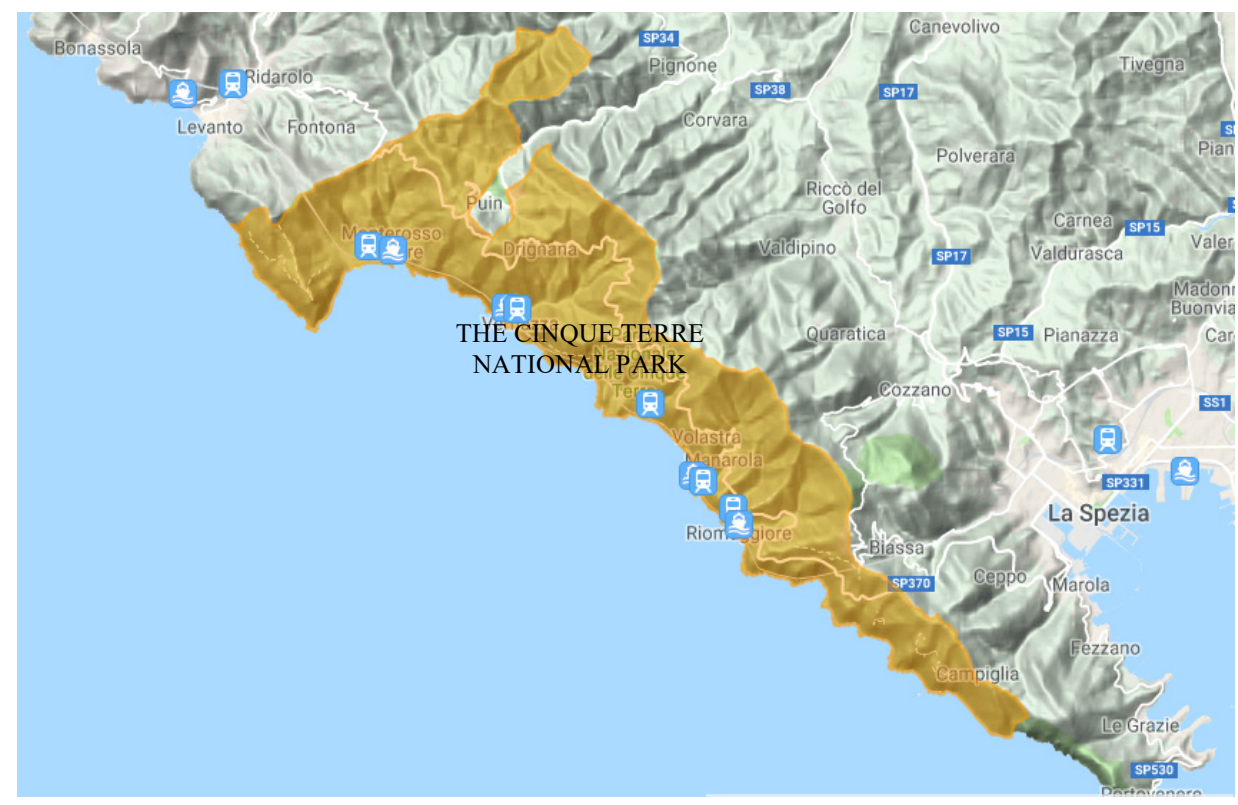

Figure 2: Cinque Terre National Park. (Source: parconazionale5terre.it.) 
stretches along the coast for about 30 kilometres, from the neighbourhood of Voltri to Nervi; and for 10 kilometres from the coast to the north along the valleys of Polcevera and Bisagno. Genoa generates approximately $6.4 \%$ of Italy's GDP $(24.618 .642 .500 €)$ and it is the fifth most productive metropolitan city; after Rome, Turin, Milan and Venice.

Genoa is one of the most famous examples of a port-city. The port of Genoa is beautifully located between the Ligurian Sea and the Apennine Mountains. While it seeks to keep its port and port-related industries competitive, Genoa is developing new components of the post-industrial economy, such as culture and creative industries, technology and research, and tourism.

The historic centre of Genoa is one of the largest in Europe, it unwinds into an intricate maze of alleyways (called caruggi) that open unexpectedly onto small squares; the soul of the city lives here in these alleyways, where the smells, tastes, and cultures have combined throughout history. In these narrow spaces, tucked away between the hills and the sea, the pride of wealthy Genoese merchants, indomitable leaders of the Republic, are beautiful mansions they built in which works of art have been collected and preserved for centuries. These are visible to this day in several house-museums (Fig. 3).

In the city centre, where time seems to have stood still, noble palaces and splendid churches alternate with historic shops that have been in operation for over 100 years, where local specialities are still prepared according to ancient recipes and handmade objects are crafted with timeless skill. It is a real labyrinth of ancient lanes, palaces, medieval walls, turrets and bell towers.

Regarding the main tourist attractions in Genoa, there is the Acquario di Genova, which is the largest aquarium in Europe and the most visited site in the Genoa city centre. It welcomes more than 900,000 visitors each year. Another tourist attraction is the Strada nuova and the system of the Palazzi dei Rolli in Genoa's historic centre, dated from the late 16th and early 17th centuries when the Republic of Genoa was at the height of its financial and seafaring power. Porta Soprana and Casa di Colombo (Cristoforo Colombo or Christopher Columbus's house), Piazza de Ferrari and the Palazzo Ducale, the old port Porto Antico, the San Lorenzo Cathedral, the Vicoli, Galata, the Palazzo Reale and via Balbi, and the national gallery in the Palazzo Spinola are some of the most important tourist attractions. Genoa has the ground available for the development of new, sustainable itineraries to discover: it has historical small shops and markets (for a food and wine experience); multi-ethnic everyday life (migrant tour); Genoa's forts and city wall; and local traditions (experiential tourism).

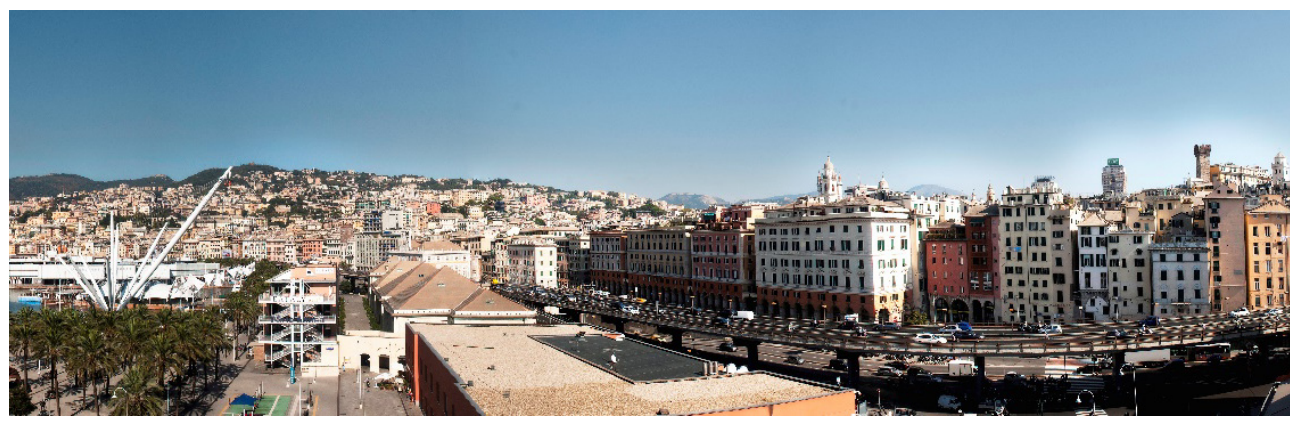

Figure 3: The historic centre of Genoa and the Old Port. 
In the last few years, tourism experienced continued growth and a deepening diversification, to become one of the fastest-growing economic sectors in the city. Tourism generates 601 million $€$ (euros) per year (442 million $€$ by Italians and 159 million $€$ from foreign visitors), which is approximately $2.5 \%$ of Genoa's GDP. This value is even higher if we consider the entire Liguria region, where tourism is responsible for $7.8 \%$ of the regional GDP.

In Genoa, tourists spend an average of $72 €$, according to the data collected by the regional monitoring centre. The Municipality of Genoa has recognized tourism as a strategic factor for sustainable development with regard to economic, social, cultural and environmental aspects. For this reason, quantification of the tourist carrying capacity of Genoa is necessary for the management of tourism growth (the authors cooperated with the Municipality of Genoa on a project called ALTER ECO, alternative tourist strategies to enhance the local sustainable development of tourism by promoting Mediterranean Identity (Interreg MED).

To calculate the tourism carrying capacity of the two case studies, the authors defined the limits of area under study:

For Cinque Terre, we chose to calculate an average value considering at the same time the areas most subject to mass tourism phenomena (the Municipality of the Cinque Terre was considered. Corniglia and Manarola were included within the municipality of Vernazza and Riomaggiore).

For the city of Genoa, we considered the area of the Old Port and the new waterfront designed by Renzo Piano. After that, the authors collected all the data needed to calculate the carrying capacity using the linear programming model (Table 1). The system of equations was solved using LINDO 6.11 software.

To maximize the income function, it is necessary to define the spending power associated with the three types of visitors. The estimated results are shown in Table 2.

The linear programming problem to be solved for determining the maximum tourist reception capacity is therefore calculated through the resolution of the systems shown in Fig. 4.

The variables TH, NTH and E are obtained using the values shown in Table 3.

Using the results obtained, it is possible to compute the maximum number of people that can visit a destination at the same time. The average daily carrying capacity for the Cinque Terre region is 3,650 people and for Genoa, is 18,176 people. To complete this research, the authors compared the results obtained with the average daily tourist presence registered by the Regional Observatory on Tourism: about 8,000 visitors for the Cinque Terre region and 3,000 for Genoa.

The tourist load in Cinque Terre is more than double compared to the limit calculated to ensure sustainable tourism. This situation is even more serious, considering that future scenarios state that the number of tourists will increase in the coming years; therefore, it is necessary to drastically reduce the incoming flow of tourists to Cinque Terre.

1,761 excursionists and 1,224 visitors cross the city centre of Genoa every day (on average). An exception was registered in 2016, during Easter break: in the city centre of Genoa there were more than 23,300 tourists because there were five cruise ships in the port, with about 4,000 passengers each. Considering these data, it is evident that Genoa usually does not exceed its carrying capacity, but as the situation is changing rapidly, a plan to regulate and support sustainable tourism is needed. In order to safeguard the Mediterranean identity of Genoa, cruise ship access to the port should be regulated. 
Table 1: Carrying capacity computations.

\begin{tabular}{|c|c|c|c|c|c|}
\hline \multirow{2}{*}{$\begin{array}{l}\text { Carrying } \\
\text { capacity } \\
\text { computed }\end{array}$} & \multicolumn{4}{|c|}{ Cinque Terre National Park } & \multirow[b]{2}{*}{ Genoa City Centre } \\
\hline & \begin{tabular}{|c|} 
Rio \\
Maggiore
\end{tabular} & $\begin{array}{l}\text { Monte } \\
\text { Rosso }\end{array}$ & Vernazza & Total & \\
\hline Residents & 1,542 & 1,468 & 852 & 3,862 & $\begin{array}{c}\text { Maddalena }-4,924 \\
\text { Molo }-7,667 \\
\text { Portoria }-9,012 \\
\text { Presan }-6,862 \\
\text { Vincenzo }-7,530 \\
\text { Porto }-215 \\
\text { TOTAL: } 36,210 \\
\end{array}$ \\
\hline $\begin{array}{l}\mathrm{P} \text { - Parking } \\
\text { facilities }\end{array}$ & 750 & 500 & 150 & 1,400 & 12,080 \\
\hline L-Launches & 1,500 & 1,890 & 1,830 & 5,220 & 28,520 \\
\hline $\begin{array}{l}\mathrm{T}-\text { Public } \\
\text { transportation }\end{array}$ & & & & $\begin{array}{c}16,30 \\
0\end{array}$ & $\begin{array}{c}116 \text { people for each bus } \\
\text { Bus Lines between Brignole and } \\
\text { Principe, stopping in De Ferrari: } \\
-18-6 \text { buses in an hour } \\
-20-6 \text { buses in an hour } \\
-35-6 \text { buses in an hour } \\
-36-4 \text { buses in an hour } \\
-37-4 \text { buses in an hour } \\
\text { Brignole/Castelletto (annunziata) } \\
-39-4 \text { buses in an hour } \\
\text { Brignole/Castelletto (annunziata) } \\
-40-4 \text { buses in an hour } \\
\text { Brignole/Castelletto (annunziata) } \\
\text { Total buses/ hr = 34 } \\
\text { Maximum people carried in } 12 \text { hrs }= \\
\text { (116 x 34) } 12=47,328 \\
\end{array}$ \\
\hline \begin{tabular}{|l|} 
HB number of \\
beds in hotel \\
\end{tabular} & 227 & 966 & 70 & 1,263 & 5,136 \\
\hline \begin{tabular}{|l} 
NTH \\
$n$ beds in \\
extra-hotel \\
situations \\
\end{tabular} & 821 & 466 & 636 & 1,923 & 2,070 \\
\hline $\begin{array}{l}\text { WD garbage } \\
\text { (t/residents/ } \\
\text { day) }\end{array}$ & 2.26 & 3.36 & 3.27 & 11.2 & $\begin{array}{l}\text { Waste production: } 515 \mathrm{~kg} / \mathrm{resident} / \mathrm{yr} \\
\text { Waste production: } 1.4 \mathrm{~kg} / \mathrm{resident} / \\
\text { day (Source: ISPRA) } \\
\text { Residents }=36,210 \\
\text { Total waste production in a day in the } \\
\text { city centre }=1.4 \times 3,210=50,624 \mathrm{t} \\
\end{array}$ \\
\hline $\begin{array}{l}\text { SMV number } \\
\text { of people in } \\
\text { critical sites }\end{array}$ & & & & 4,790 & $\begin{array}{l}\text { Critical area: Porto Antico- } \\
\text { Caricamento } \\
\text { Total square meters }=15,307 \\
\text { Crowding index }=0.7 \\
\text { Max. people }=10,714\end{array}$ \\
\hline
\end{tabular}


Table 2: Daily individual expenditures by tourist type.

\begin{tabular}{|l|l|l|l|}
\hline $\begin{array}{l}\left(\mathrm{c}_{1}, \mathrm{c}_{2}, \mathrm{c}_{3}\right) \text { Tourist } \\
\text { daily individual } \\
\text { expenditure }\end{array}$ & $\begin{array}{l}\text { Hotel tourist } \\
\text { expenditure }(\mathrm{TH}) \\
\mathrm{c}_{1}\end{array}$ & $\begin{array}{l}\text { Extra-hotel tourist } \\
\text { expenditure }(\mathrm{NTH}) \\
\mathrm{c}_{2}\end{array}$ & $\begin{array}{l}\text { Trippers } \\
\text { expenditure }(\mathrm{E}) \\
\mathrm{c}_{3}\end{array}$ \\
\hline $\begin{array}{l}\text { Cinque Terre } \\
\text { National Park }\end{array}$ & $120 € /$ day & $70 € /$ day & $40 € /$ day \\
\hline Genoa City Centre & $120 € /$ day & $65 € /$ day & $30 € /$ day \\
\hline
\end{tabular}

\begin{tabular}{|c|c|}
\hline \multicolumn{2}{|c|}{$\begin{array}{c}\text { CARRYING CAPACITY } \\
\text { CALCULATED USING THE LINEAR PROGRAMMING }\end{array}$} \\
\hline $\begin{array}{ll}\text { Cinque Terre National } \\
\text { Park } \\
\text { - } \mathrm{HB}=1263 \\
\text { - } \mathrm{NHB}=1923 \\
\text { - } \mathrm{L}=5220 \\
\text { - } \mathrm{P}=1400 \\
\text { - } \mathrm{T}=16300 \\
\text { - } \mathrm{WD}=11200 \\
\mathrm{SMW}=4790\end{array}$ & $\begin{array}{l}\max \mathrm{f}(\mathrm{x})=120 \mathrm{TH}+70 \mathrm{NTH}+40 \mathrm{E} \\
\qquad \begin{array}{l}\mathrm{TH}<1263 \\
\mathrm{NTH}<1923 \\
1.00 \mathrm{TH}+0.75 \mathrm{NTH}+0.5 \mathrm{E}<5220 \\
0.33 \mathrm{TH}+0.33 \mathrm{NTH}+0.75 \mathrm{E}<1400 \\
\mathrm{TH}+\mathrm{NTH}+2.00 \mathrm{E}<16300 \\
2.30 \mathrm{TH}+2.00 \mathrm{NTH}+0.70 \mathrm{E}<11200 \\
0.47 \mathrm{TH}+0.30 \mathrm{NTH}+0.70 \mathrm{E}<4790\end{array}\end{array}$ \\
\hline $\begin{array}{cl}\text { Genoa City Centre } \\
-\mathrm{HB}=5136 \\
\text { - } \mathrm{NHB}=2070 \\
\text { - } \mathrm{L}=28520 \\
\text { - } \mathrm{P}=12080 \\
\text { - } \mathrm{T}=68208 \\
\text { - } \mathrm{WD}=50624 \\
\mathrm{SMW}=10714\end{array}$ & $\begin{array}{l}\max f(x)=120 \mathrm{TH}+65 \mathrm{NTH}+30 \mathrm{E} \\
\qquad \begin{array}{l}\mathrm{TH}<5136 \\
\mathrm{NTH}<2070 \\
1.00 \mathrm{TH}+0.75 \mathrm{NTH}+0.5 \mathrm{E}<28520 \\
0.33 \mathrm{TH}+0.33 \mathrm{NTH}+0.75 \mathrm{E}<12080 \\
\mathrm{TH}+\mathrm{NTH}+2.00 \mathrm{E}<68208 \\
2.30 \mathrm{TH}+2.00 \mathrm{NTH}+0.70 \mathrm{E}<50624 \\
0.47 \mathrm{TH}+0.30 \mathrm{NTH}+0.70 \mathrm{E}<10714\end{array}\end{array}$ \\
\hline
\end{tabular}

Figure 4: Carrying capacity calculated using Linear Programming (LP).

Table 3: Computation of the variables TH, NTH and E.

\begin{tabular}{|l|l|l|l|}
\hline Case studies & Tourists/excursionist & Carrying capacity & $\begin{array}{l}\text { Average daily } \\
\text { tourist number }\end{array}$ \\
\hline $\begin{array}{l}\text { Cinque Terre } \\
\text { National Park }\end{array}$ & $\begin{array}{l}\mathrm{TH}=1,263 \\
\mathrm{NTH}=1,923 \\
\mathrm{E}=464\end{array}$ & $\begin{array}{l}3,650 \text { visitors per } \\
\text { day }\end{array}$ & 8,000 \\
\hline Genoa city centre & $\begin{array}{l}\mathrm{TH}=5,136 \\
\mathrm{NTH}=2,070 \\
\mathrm{E}=10,970\end{array}$ & $\begin{array}{l}18,176 \text { visitors per } \\
\text { day }\end{array}$ & 3,000 \\
\hline
\end{tabular}




\section{CONCLUSIONS}

In defining tourism carrying capacity, several critical issues emerged regarding the methodology used by the authors in the calculation of the parameters, useful for solving the equations of the Linear Programming Model. There is no single method given in the literature for calculating the required parameters. For example, it might be interesting to set a time limit for calculating the carrying capacity of public transportation or to specify how to quantify the public waste collection service.

Once the carrying capacity of a specific tourist destination has been calculated, a STAP should promote measures and strategies to use, to never exceed the optimal number of tourists. If managed correctly, tourism could be the best ally to help improve conservation and preservation of a destination. In a 2015 resolution, the European Parliament stated that "European tourism must make a transition from a model of quantitative growth to a qualitative model leading to steady and sustainable development, with a focus on qualified jobs, diversification of tourism in rural and coastal areas, and sustainable employment".

The city centre of Genoa does not normally exceed its carrying capacity. For this reason, the STAP of this area should define measures meant to develop this tourist attraction. The number of tourists could always be increased, while respecting sustainability principles.

With regards to Cinque Terre, new measures should be introduced by the STAP in order to manage tourist arrivals. Excessive overcrowding is degrading the local environment and culture. Alternative routes should be considered, to disperse tourism's economic benefits to marginal areas such as Levanto, Bonassola and Framura. It is also fundamental to change the seasonal pattern of tourism. Combating seasonality is a difficult task and few places have managed to do this effectively over the long term. It needs integrated efforts, not only with respect to cruise ships, trains, and other forms of transportation; but also with the full range of accommodation and other facilities being available throughout the year. Only a good STAP could tackle these efforts.

\section{REFERENCES}

[1] United Nations World Tourism Organization (UNWTO), Tourism Highlights, 2017. ISBN: 978-92-844-1901-2.

[2] Weaver, D.B., Asymmetrical dialectics of sustainable tourism: Toward enlightened mass tourism. Journal of Travel Research, 53(2), pp. 131-140, 2014.

[3] European Union, Sustainable Tourism in the Mediterranean, 2012. ISBN: 978-92895-0667-0.

[4] Manera, C., Pohl, M. \& Segreto, L., Europe at the Seaside, the Economic History of Mass Tourism in the Mediterranean, Berghahn Books: New York, 2009.

[5] Borelli, S., Minestrini, S. \& Guarrera, L., Responsible Tourism in the Mediterranean. Principles and Codes of Conduct, World Wide Fund for Nature: Rome, pp. 1-17, 2000.

[6] Griffin, T., Harris, R. \& Williams, P., Sustainable Tourism, A Global Experience, Elsevier Science: Oxford, 2002.

[7] World Tourism Organization (WTO), The Carrying Capacity, 1981.

[8] Coccossis, H. \& Mexa, A., Defining, Measuring and Evaluating Carrying Capacity in European Tourism Destinations, Environmental Planning Laboratory of the University of the Aegean: Athens, 2002.

[9] Zadeh, L., Fuzzy logic, neural networks, and soft computing. Commun. ACM, 37(3), ACM: New York, USA, pp. 77-84, 1994. 
534 Sustainable Development and Planning X

[10] Pirlone, F. \& Spadaro, I., A sustainable tourism action plan in the Mediterranean coastal areas. International Journal of Sustainable Development and Planning, 12, pp. 995-1005, 2017.

[11] AA.VV., A First Survey of Existing Tools and Methods for Diagnosis, Modelling and Evaluation of Tourist Destinations, Deliverable D.3.1, ALTER ECO, 2017. 